
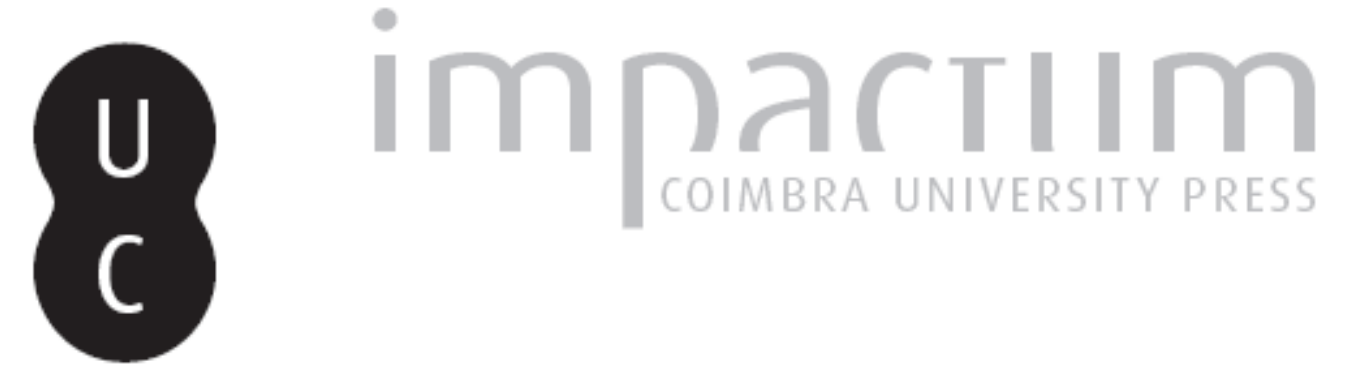

\title{
Notas para uma hermenêutica feminista da tradição cristã
}

Autor(es): $\quad$ Toldy, Teresa Martinho

Publicado por: $\begin{aligned} & \text { Instituto de História Económica e Social, Faculdade de Letras da } \\ & \text { Universidade de Coimbra }\end{aligned}$

URL

persistente:

URI:http://hdl.handle.net/10316.2/11969

DOI:

DOI:http://dx.doi.org/10.14195/0870-4147_40_8

Accessed : $\quad$ 26-Apr-2023 03:04:10

A navegação consulta e descarregamento dos títulos inseridos nas Bibliotecas Digitais UC Digitalis, UC Pombalina e UC Impactum, pressupõem a aceitação plena e sem reservas dos Termos e Condições de Uso destas Bibliotecas Digitais, disponíveis em https://digitalis.uc.pt/pt-pt/termos.

Conforme exposto nos referidos Termos e Condições de Uso, o descarregamento de títulos de acesso restrito requer uma licença válida de autorização devendo o utilizador aceder ao(s) documento(s) a partir de um endereço de IP da instituição detentora da supramencionada licença.

Ao utilizador é apenas permitido o descarregamento para uso pessoal, pelo que o emprego do(s) título(s) descarregado(s) para outro fim, designadamente comercial, carece de autorização do respetivo autor ou editor da obra.

Na medida em que todas as obras da UC Digitalis se encontram protegidas pelo Código do Direito de Autor e Direitos Conexos e demais legislação aplicável, toda a cópia, parcial ou total, deste documento, nos casos em que é legalmente admitida, deverá conter ou fazer-se acompanhar por este aviso.

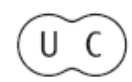



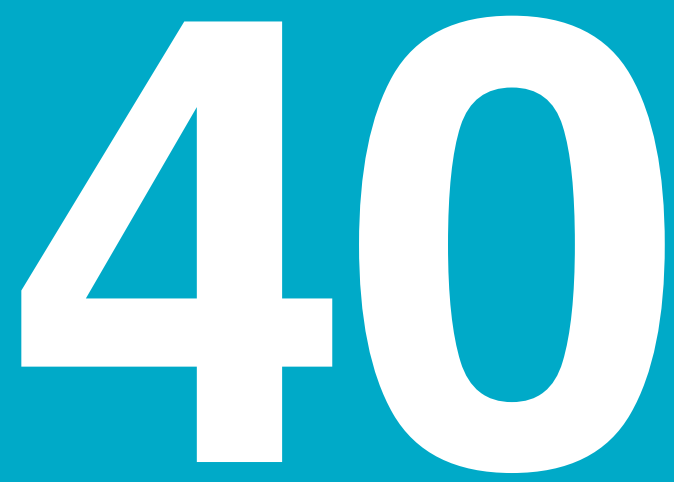

\section{Revista Portuguesa de História}

Faculdade de Letras da Universidade de Coimbra Instituto de História Económica e Social

Coimbra 08/09 


\title{
Notas para uma hermenêutica feminista da tradição cristã
}

\author{
Teresa Martinho Toldy
}

Universidade Fernando Pessoa

\section{Contornos de uma "teologia feminina"}

O Wörterbuch der feministischen Theologie, fruto de um trabalho que congregou mais de setenta especialistas de língua alemã, define a teologia feminista nestes termos: "A teologia feminista é uma teologia de mulheres de orientação feminista que pretendem reconhecer, identificar, criticar e ultrapassar o patriarcalismo tanto na sociedade, como na Igreja"1.

O que significa "uma teologia de mulheres de orientação feminista?" Antes de mais, que não se trata de uma teologia acerca da mulher ("Teologia da mulher"), a partir de uma eventual descrição essencialista da mesma, baseada numa compreensão da sua "natureza" como algo inscrito no plano de Deus para a humanidade, e, portanto, imutável ou, no mínimo, imune à possibilidade de alteração por parte dos seres criados. O Magistério recente da Igreja Católica no que às mulheres diz respeito, nomeadamente, posterior ao Concílio Vaticano II,

1 Halkes, C. \& Meyer-Wilmes, H. (1991), "Feministische Theologie/Feminismus/ Frauenbewegung", in: Gössmann, E., Moltmann-Wendel, E., Pissarek-Hudelist, H. et al. (eds), Wörterbuch der feministischen Theologie, Gütersloh: Gütersloh Verlag, p. 102. 
constitui um exemplo deste tipo de teologia "feminina". Este tipo de abordagem tem consequências para as mulheres concretas, perpetuando, concretamente, as desigualdades e a desconfiança face à relevância da experiência histórica para a auto-compreensão da mulher, já que contrariar a natureza humana é contrariar o plano de Deus acerca do ser humano, plano esse que explicita uma vontade que deve ser cumprida em todos os níveis da vida humana, quer seja na vida social, quer seja na vida familiar ou pessoal.

O Magistério mais recente abandonou o discurso explícito de afirmação da desigualdade entre o homem e a mulher que era típico antes do Concílio Vaticano II: veja-se, por exemplo a convicção de Pio XI de que haveria uma "determinada desigualdade e graduação" no interior da família como resultante da "vontade de Deus"2. Ou ainda Pio XII, que afirmando já a igual dignidade e valor do homem e da mulher, continuava a insistir na ideia de que estes "não são iguais em tudo", uma vez que existem "determinados dons, inclinações e disposições naturais mais próprias do homem ou da mulher" e que "a natureza lhes atribuiu domínios e trabalhos distintos"3.

As afirmações do Magistério acerca da natureza da mulher inserem-se neste horizonte de compreensão. A sua preocupação é encontrar "a especificidade do feminino", tal como ela é ditada pela natureza. O discurso acerca da natureza humana implicará sempre estas duas vertentes: a afirmação da igualdade do homem e da mulher, ambos possuidores da mesma natureza, e a diferença entre ambos, a qual determina a sua desigualdade.

2 Pio XI, Casti connubii, in: AAS 22 (1930) 568: "Mas, a igualdade de direitos, que actualmente é exigida de forma exagerada, consiste nos direitos da pessoa e da dignidade humana e no que resulta do contrato e que é próprio do matrimónio; nisso, ambos os esposos têm, de facto, os mesmos direitos e os mesmos deveres, mas, nas outras coisas, tem que existir uma certa desigualdade e hierarquia, como o exigem o bem da família e a necessária unidade e firmeza da comunidade e da ordem familiares. Se, num determinado país, a situação social e económica da mulher casada exigir uma alteração, em consequência de uma transformação das circunstâncias culturais, é tarefa do poder público adaptar os direitos civis da esposa às necessidades e exigências do presente, tendo em conta a especificidade da natureza feminina, da moral, da dignidade e do bem da família, mas a ordem essencial da comunidade doméstica deve permanecer intocável, dado que esta está determinada por uma autoridade e sabedoria superiores às humanas, quer dizer, uma autoridade e sabedoria divinas, não podendo, portanto, ser submetida a qualquer alteração resultante de leis civis e de critérios humanos".

3 Cf. Pio XII, Allocutio ad puellas ab actione catholica ex Italiae dioecesibus Romae coadunatas, anno vicesimoquinto exeunte ab inito earumdem apostolatu, 24 ap. 1943, in: AAS 35 (1943) 137-138. 
Contudo, o Papa Paulo VI, por exemplo, ainda falava da necessidade de afirmar as "distinções estabelecidas pelo Criador" como forma de "proteger a sua (das mulheres) vocação própria"4 . João Paulo II, por sua vez, desenvolveu uma reflexão que insiste na ideia de complementaridade. Esta fundamenta-se na constituição biológica do homem e da mulher, constituição esta que faz parte do plano de Deus e que determina a existência da mulher para o homem e do homem para a mulher. Ora o elemento constitutivo da feminilidade é a maternidade. A mulher identifica-se pela "disposição natural" que o seu organismo tem de servir a geração e o nascimento do ser humano ${ }^{5}$. Sendo assim, a complementaridade parece revelar-se, antes de mais, fisicamente. A vontade de Deus é que a mulher seja aquela na qual a ordem do amor do mundo criado das pessoas encontra um terreno para deitar a sua primeira raiz ${ }^{6}$.

Apesar de João Paulo II afirmar que "o gerar humano é comum ao homem e à mulher" ", acrescenta que a parentalidade se realiza de uma forma mais vinculativa na mulher, uma vez que é ela que faz a gestação da criança. Isto conduz a afirmar que "o homem deve aprender da mãe a sua própria "paternidade"" Estes textos fazem duas afirmações fundamentais. Primeiro, que o homem e a mulher se definem reciprocamente. Depois, que a sua complementaridade é determinada fisicamente. No entanto, parece poder concluir-se da quase total ausência de reflexão sobre o significado das características masculinas para o "ser-homem" que existe uma associação mais directa da definição de mulher às suas determinações físicas. Além disso, poder-se-á perguntar se a ideia de complementaridade não corre o risco de reduzir o homem e a mulher a duas metades incompletas. Deste risco parece aperceber-se o próprio Catecismo da Igreja Católica ao dizer que, o facto do homem e da mulher serem feitos um para o outro, não significa que Deus os tenha concebido como duas metades ou como seres incompletos ${ }^{9}$. No entanto, o mesmo Catecismo reafirma a ideia de complementaridade baseada nas determinações sexuais do homem e da mulher.

A natureza biológica da mulher parece ser extrapolada para a sua natureza espiritual. Os textos traçam o retrato espiritual feminino a partir da condição de mãe: a mulher possui o amor à vida, o sentimento de protecção do berço.

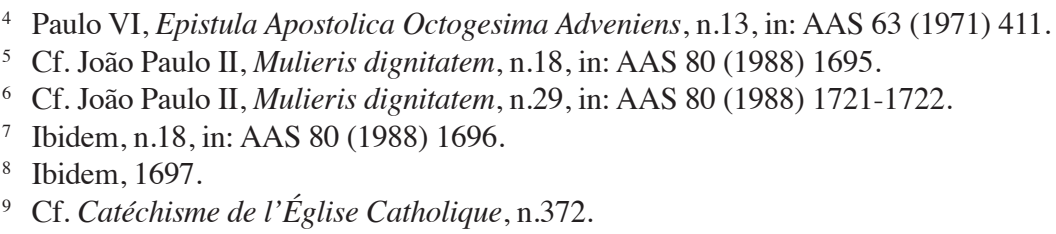


Ela conhece o mistério da vida ${ }^{10}$. Ela tem a missão de "colocar bálsamo nas feridas abertas da humanidade" ". Uma vez que a lei da natureza é eterna, estas características da mulher constituem a sua "essência perene"12, a sua "verdade"13. Elas são "imutáveis e não se desactualizam" 14 , uma vez que constituem o plano de Deus para as mulheres ${ }^{15}$.

À objecção de que muito daquilo que é atribuído à natureza da mulher pode ser produto cultural e histórico, o Papa Paulo VI responde que "a história e a natureza estão estreitamente ligadas uma à outra" ${ }^{16}$. Neste contexto, os textos do Magistério revelam sempre o temor de que os movimentos de emancipação da mulher desvirtuem a mulher, pois que, no caso de lutarem por uma igualdade entre o homem e a mulher que procura mudar "aquilo que a natureza exige do homem e aquilo que a natureza exige da mulher ${ }^{17 \%}$, desrespeitam esta ordem estabelecida pelo Criador.

${ }^{10}$ Cf. Concilium Oecumenicum Vaticanum II, Nuntii ab E.mis Patribus Cardinalibus lecti et a Summo Pontifice iis traditi qui variarum socialum ordinum personam gerebant. Aux femmes, in: AAS 58 (1966) 14.

${ }^{11}$ Pio XII, Audiência às participantes no Congresso feminino Internacional da Acção Católica, 15.04.1939, in: OR 90 (15 Abril 1939) 1.

${ }^{12}$ João Paulo II, Christifideles laici, n.50, in: AAS 81 (1989) 490.

${ }^{13}$ Cf. Pio XII, Audiência Geral, 24.02.1942, in: OR 47 (26 Fevereiro 1942) 1: "uma verdade antiga e sempre nova, radicada na própria situação física da vida da mulher".

${ }^{14}$ João Paulo II, Mulieris dignitatem, n.30, in: AAS 80 (1988) 1726.

${ }^{15}$ Cf. João Paulo II, Ad episcopos Civitatum Foederatarum Americae Septemtrionalis missus, in: AAS 81 (1989) 1165.

${ }^{16}$ Paulo VI, Carta ao Presidente da 59 ${ }^{a}$. Sessão da Semana Social da França, Sr. Alain Barrière, in: OR 153 (5 Julho 1972) 1.

${ }^{17}$ Sacra Congregatio Pro Doctrina Fidei, Declaratio De abortu procurato, n. 15, in: AAS 66 (1974) 740. Cf. ainda: Pio XI, Casti connubii, in: AAS 22 (1930) 549, 567-568; Pio XII, Ad Delegatas Unionis internationalis Sodalitatum mulierum catholicarum ob communem Conventum Romae coadunatas, in: AAS 39 (1947) 480-488; Mulieribus peregrinationis causa ad sanctuarium lauretanum B. Mariae Virginis e tota Italia coadunatis, ad fausta anniversaria Summi Pontificis Pii XII pie celebranda, in: AAS 48 (1956) 779-786; Paulo VI, Octogesima Adveniens, n.13, in: AAS 63 (1971) 410; João Paulo II, Laborem Exercens, n.19, in: AAS 73 (1981) 627-628; Christifideles laici, n.50, in: AAS 81 (1989) 490; Ad episcopos Civitatum Foederatarum Americae Septemtrionalis missus, in: AAS 81 (1989) 1165; Ad eos qui conventui consociationum "Pro vita" ab omnibus nationibus interfuerunt coram admissos, in: AAS 84 (1992) 1061-1065; Mulieris dignitatem, n.10, in: AAS 80 (1988) 1674-1677; Joseph Ratzinger, Apertura del Consistoro Straordinario, in: OR, 5/04/1991. 


\section{As perspectivas das teologias feministas}

A teologia feminista, por seu turno, considera-se a si mesma como uma teologia "de mulheres para mulheres": o sujeito e o receptor são as mulheres. Porém: "mulheres de orientação feminista" 18 . Significa isto que não se concentra tanto em fenómenos individuais, ou numa busca da "natureza feminina", como, sobretudo, numa perspectiva colectiva, social, comunitária, proveniente dos movimentos das mulheres, mais concretamente, dos movimentos feministas, organizados para reivindicar os seus direitos sociais.

O que significa, pois, colocar a teologia numa perspectiva feminista? Antes de mais, o reconhecimento de que não existe ciência sem perspectivação da mesma a partir do local de onde é enunciada. Esta descoberta, diga-se, não se deve directamente à teologia feminista, mas sim à epistemologia crítica, da Escola de Frankfurt, bem como às epistemologias feministas, que, inserindo-se no movimento de reconhecimento da crise epistemológica do modelo da "objectividade científica", afirmam o cariz "situado" de todo o conhecimento. Autoras como, por exemplo, Sandra Harding ${ }^{19}$ chamam a atenção para a "agenda" sócio-política de todo o conhecimento, nomeadamente, para a sua contextualização em projectos androcêntricos ou eurocêntricos ou, pelo contrário, em projectos feministas e anti-racistas. Estas abordagens à investigação rejeitam a possibilidade de alguém ser capaz de falar sem ser a partir de um determinado local histórico ou social, naquilo que Donna Haraway designa como "the God trick of modern philosophies of science" ${ }^{20}$, isto é, a pretensão de uma visão panorâmica, universal e a-temporal.

A ciência convencional ignora que não existe conhecimento sem contexto, que o sujeito produtor de conhecimentos tem sempre um contexto cultural, social, político e económico que influencia a sua forma de ver o mundo. Como Raimundo Pannikar ${ }^{21}$ diz, acerca do discurso dos direitos humanos: não podemos partir do princípio de que a paisagem que avistamos através da nossa janela corresponde à realidade em si. Não podemos esquecer que estamos a ver através de uma janela e não devemos pensar que estamos a céu aberto.

${ }^{18}$ Halkes, C. \& Meyer-Wilmes, H. (1991), "Feministische Theologie/Feminismus/Frauenbewegung”, in: Gössmann, E., Moltmann-Wendel, E., Pissarek-Hudelist, H. et al. (eds), Wörterbuch der feministischen Theologie, Gütersloh: Gütersloher Verlag, p. 102.

${ }^{19}$ Harding, S. (2006). Science and Social Inequality: Feminist and Postcolonial Issues, Urbana and Chicago: University of Illinois Press, p. 83.

${ }^{20}$ Cit. in: Harding, S., ibidem.

${ }^{21}$ Pannikar, R. (1982), "Is the Notion of Human Rights a Western Concept?", 120 Diogenes 78 (Winter 1982). 
Normalmente, são apresentadas duas objecções a isto que se tem convencionado chamar "standpoint theory" (Sandra Harding resume o significado desta abordagem dizendo que ela se baseia na consciência de que "a ordem social parece diferente do ponto de vista das nossas vidas e das nossas lutas" ${ }^{22}$ ): primeiro, que esta teoria não tem objectividade. Em segundo lugar, que conduz ao relativismo. Harding distingue entre "objectividade forte" (strong objectivity) e "objectivismo fraco" ${ }^{23}$, dizendo que só quando estamos conscientes do enviesamento resultante do facto de produzirmos conhecimento do nosso ponto de vista é que somos capazes de reconhecer que a nossa ciência é limitada - e isto constitui a porta aberta para adquirir maior objectividade. Em segundo lugar, "a objectividade forte", resultante de uma abordagem auto-crítica, é diferente do "objectivismo fraco", que se baseia na convicção de que o nosso conhecimento poderia fazer o "God trick" já mencionado, isto é, pretender ser universal. Esta consciência da relatividade do conhecimento não significa aceitar o relativismo, já que reconhecer que todas as formas de conhecimento são parciais não é o mesmo que aceitar que qualquer uma serve, sem ter em conta o impacto dos diversos tipos de conhecimento sobre as diversas comunidades humanas. A maximização da objectividade exige não só que representemos com rigor a forma como nos vemos a nós próprios, aos outros e ao mundo, mas também que levemos a sério as representações que os outros têm de nós, de si próprios e do mundo. O que importa, hoje, é identificar o que é conhecimento útil e conhecimento fútil ${ }^{24}$, bem como quem está qualificado para usar e decidir sobre este conhecimento.

A teologia política alemã (sobretudo $M \mathrm{Met}^{25}$ ), influenciada, por sua vez, também pela Escola de Frankfurt, contribuiu de forma decisiva para a compreensão de que não existe teologia - e o mesmo se pode dizer de qualquer outro saber - que não seja resultado do diálogo entre conceitos fundamentais, património da comunidade científica global, e o contexto no qual o investigador se

${ }^{22}$ Harding, S. (2004), "Introduction: Standpoint Theory as a Site of Political, Philosophic, and Scientific Debate", in: The Feminist Standpoint Theory Reader: Intellectual and Political Controversies, Londres: Routledge, p. 3.

${ }^{23}$ Harding, S. (2006). Science and Social Inequality: Feminist and Postcolonial Issues, Urbana and Chicago: University of Illinois Press, p. 83.

${ }^{24}$ Cf. Santos, B. S.; Meneses, P. \& Nunes, J. A. (2004). "Introdução: Para ampliar o cânone da ciência: a diversidade epistemológica do mundo", in: Reinventar a Emancipação Social: para novos manifestos", vol. IV, Porto: Edições Afrontamento, p. 40.

${ }^{25}$ Cf., por ex., Metz, J. (1977), Glaube in Geschichte und Gesellschaft. Studien zu einer praktischen Fundamentaltheologie, Mainz: Matthias Grünewald Verlag. 
encontra inserido. Este contexto inclui as opções ideológicas, políticas, culturais, éticas, etc. A consciencialização do carácter contextual da teologia constitui um passo decisivo para a identificação, nomeadamente, dos androcentrismos veiculados como "visões antropológicas", isto é, para a identificação de visões parciais e parcelares que foram apresentadas pelos dominadores do discurso como perspectivas totalizantes.

Essencial para a perspectivação deste carácter situado de todo o discurso teológico é a utilização da categoria da "experiência". Apesar de se tratar de algo fluido, "obscuro", parafraseando Gadamer ${ }^{26}$, a "experiência" constitui um dos conceitos-chave da teologia feminista. Valerie Saiving ${ }^{27}$ foi das primeiras autoras a fazer uma reflexão elaborada sobre a influência da experiência masculina e feminina sobre o discurso teológico. Este estudo é ainda marcado pela diferenciação sexual como critério para avaliar a distinção existente entre ambas as experiências. Contudo, constitui um marco na história da teologia feminista, nomeadamente, na história da sua hermenêutica.

O seu principal contributo consiste em ter chamado a atenção para o carácter situado (quer seja masculino, quer seja feminino) de todo o discurso teológico. O reconhecimento da influência que o lugar onde o teólogo se encontra exerce sobre a sua reflexão teológica levanta a questão da possibilidade de um discurso teológico objectivo e universal. Os postulados para uma "investigação das mulheres" (Frauenforschung), lançados por Maria Mies no campo da sociologia, exerceram uma influência decisiva sobre a hermenêutica teológica feminista. No seu famoso texto, Methodische Postulate zur Frauenforschung, a autora defende o primado do envolvimento (Parteilichkeit ou Betroffenheit") do investigador na sua investigação sobre a "objectividade", assim como a preponderância do compromisso social sobre uma investigação distanciada ${ }^{28}$.

Também Valerie Saiving desmistifica o discurso teológico "universal", chamando a atenção para o facto de este ser directamente influenciado pela experiência do seu autor. Para esta afirmação - que, entretanto, haveria de

${ }^{26}$ Gadamer, H.-G. (1990), Wahrheit und Methode. Grundzüge einer philosophischen Hermeneutik, Tübingen: Mohr, $6^{\text {a }}$ ed, p. 352.

${ }^{27}$ Saiving, V. (1979), “The Human Situation: A Feminine View”, in: Christ, C. \& Plaskow, J. (eds.), Womanspirit Rising. A Feminist Reader in Religion, San Francisco: Harper Collins, pp. 25-42.

${ }^{28}$ Cf. Mies, M. (1978 e 1984a), "Methodische Postulate zur Frauenforschung”, in: Beiträge zur feministischen Theorie und Praxis 1, pp. 41-63 e 7, pp. 7-25. Para um exemplo da reflexão destes princípios pela teologia feminista cf. Meyer-Wilmes, W. (1991), Rebellion auf der Grenze . Ortsbestimmung feministischer Theologie, Freiburg: Herlder Verlag. A crítica da pretensa objectividade e não-envolvimento do investigador na sua investigação ocupa, ainda, um lugar decisivo na filosofia e na epistemologia feministas. 
se tornar um dado adquirido, tanto para a filosofia, como para a teologia feminista - contribuiu, igualmente, a reflexão das teologias da libertação. Estas consideram "a praxis" como o "lugar teológico fundamental" e defendem a existência de uma "dialéctica permanente entre Teoria (teológica) e Praxis (política da fé)" 29 .

Existem formas diferentes de valorizar e definir aquilo que constitui a(s) "experiência(s)" das mulheres. Carol Christ e Judith Plaskow distinguem entre "experiência de libertação" e "experiência tradicional":

"O primeiro modelo valoriza a experiência das mulheres enquanto experiência de libertação - reconhecimento da opressão, confronto com a cultura e as instituições sexistas, movimentação no sentido da liberdade. Este modelo é limitado porque não diz nada às mulheres que não têm consciência de fazerem parte de um grupo oprimido, em busca da liberdade. Por outro lado, o seu aspecto positivo consiste em permitir a afirmação da solidariedade das mulheres com outros grupos de oprimidos. [...] De acordo com o segundo modelo, as experiências tradicionais das mulheres, tal como o casamento e a maternidade, apesar de terem sido distorcidas pelo patriarcalismo, podem fornecer chaves de leitura importantes para a transformação da cultura patriarcal. As pensadoras que se concentram na experiência tradicional acreditam que esta é passível de ser integrada numa visão feminista global, apesar de ter sido rejeitada e denegrida pela cultura sexista. A perspectiva feminista deve reapropriar-se de tudo aquilo que é considerado 'feminino': a intuição, a expressão dos próprios sentimentos, a preocupação pela dimensão pessoal do relacionamento. Enquanto algumas objectariam que as experiências tradicionais das mulheres não são senão o resultado da alienação, outras acreditam que os valores das mulheres são menos alienados do que os valores dos homens." ${ }^{30}$

O denominador comum aos dois tipos de experiência referidos está numa definição global da mesma, a saber: a "experiência refere-se, simplesmente, à construção da vida tal como ela é vivida." 31 Rosemary Radford Ruether ${ }^{32}$ refere-se a um "círculo hermenêutico da experiência passada e presente" das

${ }^{29}$ Cf., por ex., Boff, C. (1982), Teologia e Prática. Teologia do Político e suas mediações, Petrópolis: Editorial Vozes, p. 22.

${ }^{30}$ Christ, C. \& Plaskow, J. (1979), Womanspirit Rising. A Feminist Reader in Religion, San Francisco: Harper Collins, p. 8.

${ }^{31}$ Ibidem, 6.

${ }^{32}$ Ruether, R.R.(1993), Sexism and God-Talk.Towards a Feminist Theology,Londres: SCM Press, p. 12. 
mulheres que consiste num movimento triplo: experiência (das mulheres) - teoria (tradição) - experiência. Assim, a experiência das mulheres constitui um "desafio" crítico à teoria (no caso da teologia, à Tradição), antes de mais, pelos motivos já enunciados por Valerie Saiving ${ }^{33}$ : a existência de experiências diversas fragmenta, já, de si, a possibilidade de um discurso genérico-abstracto, com validade para todos os tempos, quadrantes e sexos. Por isso, a experiência das mulheres - enquanto experiência de exclusão do discurso teórico dominante, predominantemente masculino - denuncia o carácter verdadeiramente parcial do discurso teórico. A experiência assume o carácter de instância crítica da teoria. A revisão dos princípios teóricos ou, eventualmente (no caso da Tradição cristã e na perspectiva das feministas não-radicais), o regresso aos seus fundamentos (isto é, ao conteúdo libertador do cristianismo) conduz a uma prática diferente. Assim, uma teoria política ou cultural que se pensa a si mesma a partir de critérios de igualdade tenderá a criar uma sociedade que se movimenta no sentido da igualdade entre as mulheres e os homens.

Em toda a hermenêutica feminista, a questão é a da suspeita do raciocínio sociocultural dominante, de redescoberta do "reverso" do tecido da construção desse mesmo raciocínio e de lógicas alternativas à lógica "que venceu", portanto, na hermenêutica feminista da tradição religiosa, trata-se de pôr a descoberto o discurso vencedor, apresentado como se radicassem numa tradição de origem, impulso, fundamentação e legitimação divinas.

\section{A tradição religiosa "tem alguma coisa a dizer ao futuro das mulheres"?}

Uma primeira leitura dos documentos oficiais da Igreja Católica não parece, contudo, indiciar uma misoginia crassa. De facto, os textos mais misóginos que nos chegaram até hoje como sendo exemplo das representações que a Igreja faz das mulheres provêm mais dos teólogos do que das instâncias oficiais da Igreja Católica. (S. Ambrósio, por exemplo, escreveu: "Foi a mulher que foi a autora do pecado para o homem, não o homem para a mulher" ${ }^{34}$. E Tertuliano, mais de cem anos antes, escreveu também, referindo-se às mulheres: "Não sabes que és Eva, tu também? A sentença de Deus para este sexo continua a estar plenamente em vigor, portanto 'o seu pecado também continua a subsistir. Tu és a porta do Diabo, tu consentiste na sua árvore, tu foste a primeira a abandonar a

\footnotetext{
${ }^{33}$ Cf. Saiving, opus cit.

${ }^{34}$ S. Ambrósio de Milão, PL 14, col. 303.
} 
lei divina" ${ }^{35}$. Nove séculos mais tarde, Geoffroy de Vendôme ${ }^{36}$ chega à mesma conclusão, depois de ter estendido a culpa da mulher à responsabilidade pela negação de Pedro (através da criada referida no relato evangélico): "Por isso, este sexo, cumprindo o seu ofício, à maneira de uma serva porteira, exclui da vida todos aqueles que seduz, como excluiu Pedro de Cristo, ou inclui-os na morte, como fez com Adão, no Paraíso". Aliás, esta associação da mulher à negação de Pedro já é conhecida no séc. IV-V: Máximo de Turim ${ }^{37}$ também se lhe refere. Os avisos do clero para que os seus membros se afastem das mulheres chegam ao ponto de a referir como "raiz do mal e de todos os vícios".)

No entanto, a leitura dos documentos propriamente emitidos pelo Vaticano, leitura que, à primeira vista, parecia legitimar a conclusão de que eles seriam "inofensivos", uma vez aprofundada, revelou sobretudo os não-ditos, ou os paralelos antitéticos entre modelos de mulher (Eva/Maria) que, dizendo o que ela deveria ser, revelam o que, de facto, elas não são. Os textos falam, então, também por aquilo que não dizem, pelas formulações pretensamente dirigidas a toda a humanidade às quais se acrescenta depois "também as mulheres", como se, quando se fala da humanidade, não se depreenda imediatamente que se fala também das mulheres. A leitura destes textos requer, portanto, uma hermenêutica da suspeita, isto é, uma hermenêutica que procura ler os textos naquilo que eles dizem e naquilo que eles omitem, pondo a descoberto a voz e os perfis dos seus autores colectivos, e retomando os fios perdidos dos/das silenciados/silenciadas, não nomeados. Evidentemente que estes textos não podem ser considerados fundacionais do Cristianismo. Mas é interessante verificar como eles relêem o que os textos fundacionais do cristianismo dizem sobre as mulheres, sobre Cristo, sobre Deus. Além disso, é ainda interessante observar o que é considerado "tradição" quando se trata de fundamentar, por exemplo, o monopólio masculino dos ministérios ordenados (muitos dos textos aqui mencionados como exemplos da misoginia dos teólogos de séculos passados são referidos, ainda que apenas em nota de rodapé, nos documentos oficiais de proibição da ordenação das mulheres, mais, de proibição da discussão da questão ${ }^{38}$.

${ }^{35}$ Tertuliano, PL 1, col. 1305.

${ }^{36}$ Geoffroy de Vendôme, PL 157, col. 126.

${ }^{37}$ Máximo de Turim, PL 57, col. 350.

${ }^{38}$ Basta ler o documento da Sagrada Congregação para a Doutrina da Fé, Inter insigniores (1977), assim como a sua reiteração na Epistola Apostolica. De Sacerdotali ordinatione viris tantum reservanda (1994). 
Além das referências à tradição teológica, os documentos que proíbem o acesso das mulheres aos ministérios ordenados fazem uma determinada interpretação dos textos bíblicos, nomeadamente, do Novo Testamento. Haveria muito a dizer sobre a exegese de determinados textos. Não é meu objectivo fazê-lo aqui. Importa só dizer que a leitura destes textos constitui um dos exemplos mais nítidos da forma como se pode conseguir que os textos digam precisamente aquilo que nós queremos que eles digam, como se fossem oráculos de sibilas...

Coloca-se, então, a questão de saber se a tradição religiosa "tem alguma coisa a dizer ao futuro das mulheres" ${ }^{\prime 39}$ ou se, para realizarem as suas potencialidades humanas, elas têm que "emigrar" para fora dessa tradição, abandonando qualquer referência religiosa ou encontrando uma "tradição alternativa".

\section{Para uma leitura desconstrutiva e reconstrutiva da tradição}

Muitos dos esforços da teologia feminista judeo-cristã têm ido precisamente no sentido da análise desconstrutiva e reconstrutiva da tradição, procurando ler nos fios dominantes, nos fios ausentes e nas "pontas soltas" o tecido de uma presença das mulheres na tradição (como elemento perturbador ou facilitador da sua transmissão) que, muitas vezes, traindo-as, traiu o seu próprio fundamento igualitário, e que, ainda que no "não teorizado" e no silêncio, passou por uma transmissão quotidianamente feminina. (Existem, por exemplo, textos sobre determinadas mulheres no Novo Testamento que, ao longo da sua transmissão, produziram uma distorção da figura das mulheres envolvidas, fazendo-as corresponder a determinados modelos estranhos ao texto. $\mathrm{O}$ caso mais conhecido é, provavelmente, o de Maria Madalena. Espontaneamente, quase toda a gente a associa ao pecado: uma prostituta convertida por Cristo. Simplesmente, não existe fundamento neotestamentário para esta interpretação. Segundo a exegese feminista tem vindo a concluir ${ }^{40}$ - no que é corroborada por exegetas homens aliás, deve dizer-se que a exegese dos textos bíblicos tem sido o domínio mais

${ }^{39}$ Este é, com efeito, o título de um relevante artigo de McLaughin,E. (1975), "The Christian Past: Does it Hold a Future for Women?”, in: Anglican Theological Review 57, pp. 36-56.

${ }^{40}$ Cf., a título de exemplo, a investigação de: Schottroff, L. (1991), "Maria Magdalena: Neues Testament”, in: Gössmann, E., Moltmann-Wendel, E., Pissarek-Hudelist, H. et al. (eds), Wörterbuch der feministischen Theologie, Gütersloh: Gütersloher Verlag, pp. 275-277; (1994), Lydias ungeduldige Schwestern. Feministische Sozialgeschichte des frühen Christentums, Gütersloh: Gütersloher Verlag; e ainda: Moltmann-Wendel, E. (1991), "Maria Magdalena in der Tradition", in: Gössmann, E., Moltmann-Wendel, E., Pissarek-Hudelist, H. et al. (eds), Wörterbuch der feministischen Theologie, Gütersloh: Gütersloher Verlag, pp. 277-279. 
receptivo às interpretações feministas, precisamente porque não é um sector da teologia tão dogmatizado como o da teologia sistemática! - Maria Madalena foi a primeira mulher importante no cristianismo. Não foi Maria, mãe de Jesus, mas sim Maria Madalena, que seguiu Jesus como discípula, que esteve junto à cruz, que foi a primeira a receber a mensagem de que Jesus tinha ressuscitado, que foi a "apóstola dos apóstolos". Ora, esta mesma Maria Madalena, à medida que o cristianismo se foi institucionalizando como Igreja e o poder e autoridade se foram estruturando cada vez mais, tornou-se progressivamente a mulher perdida que Jesus converteu...)

A hermenêutica feminista identifica a existência de uma tensão entre a prática da Igreja e o evangelho. Uma vez que o evangelho de Jesus Cristo constitui a origem da Igreja (não só em termos cronológicos, como, acima de tudo, em termos teológicos), afirmar a existência de uma divergência entre o evangelho e a Igreja é afirmar a existência de uma divergência entre a Igreja e as suas origens. Esta afirmação põe em causa não só a fidelidade da Igreja às suas origens, portanto, a sua razão de ser e a sua identidade, como também a correcção do processo de transmissão da fé, isto é, a Tradição.

A afirmação da existência de duas tradições paralelas pressupõe um conflito de interpretações da mensagem original. A solução para este conflito reside numa crítica da tradição cristã que assimilou a desigualdade propalada pelo seu contexto histórico. O papel de uma hermenêutica feminista reside, então, no estabelecimento de um confronto crítico entre a tradição igualitária, de raiz neo-testamentária, a tradição de desigualdade e a experiência das mulheres. Para tanto, a teologia feminista procede em três etapas.

Primeiro, faz uma crítica da tradição cristã "que difama as mulheres"41, isto é, da tradição que considerou a mulher inferior ao homem, ou que a associou ao mal.Esta crítica põe a descoberto a submissão a que estas foram sujeitas ao longo da história.

Segundo, procura recuperar "a história perdida das mulheres" ${ }^{42}$. Esta recuperação passa pela redescoberta das figuras femininas que constituem exemplos de fé para as mulheres crentes na actualidade.

Por último, a hermenêutica feminista revê as categorias cristãs de forma a que estas reflictam tanto a igualdade das mulheres, como a sua experiência. Apela-se aqui a uma reformulação dos conceitos teológicos fundamentais.

${ }^{41}$ Carr, A. (1990), Frauen verändern die Kirche, Christliche Tradition und feministische Erfahrung, Gütersloh: Gütersloher Verlag, p. 17.

${ }^{42}$ Idem, p. 109. 
Em suma, a hermenêutica feminista procura "um passado útil" mulheres. A questão fundamental é, portanto, a de saber se a Tradição cristã pode ser "útil", isto é, pode iluminar o presente, e se é possível construir um futuro a partir dela, assim como uma história e uma linguagem que sejam igualmente úteis, isto é, capazes de transmitirem a mensagem cristã de uma forma correcta e adequada ao contexto actual.

A tradição constitui, do mesmo modo, o processo de transmissão da Palavra. São redutoras todas as interpretações da mesma que a pretendem resumir a uma cronologia, desde as origens, até à actualidade, ou a uma repetição de acontecimentos fundacionais de tipo institucional. Com esta afirmação não se pretende pôr de lado a tradição, pelo contrário, procura-se tornar clara a necessidade de uma radicação constante da identidade na tradição. Simplesmente, esta radicação compreende-se como uma participação, melhor, uma identificação com o processo de transmissão da Palavra ao longo da história.

Numa concepção deste tipo, todos - mulheres e homens - participam na transmissão da tradição, portanto, todos são sucessores dos impulsionadores iniciais da mensagem. Esta sucessão não se compreende cronológica, mas sim teologicamente: o conteúdo essencial da mensagem fundacional actualiza-se cada vez que um ser humano ouve a Palavra e a põe em prática.

Um segundo contributo da hermenêutica feminista de uma tradição religiosa para o corpus de uma hermenêutica feminista global poderá estar, então, no treino na exploração dos textos fundadores e das suas interpretações e reinterpretações, assim como no desafio à criatividade de leituras que, despegando-se conscientemente da "letra do texto", evoluem para um modelo decididamente "não-fundamentalista", correlativo, aberto.

\section{O mundo das tradições das mulheres}

O retomar das tradições das mulheres é um processo com facetas e ênfases diversos, consoante a tendência hermenêutica que lhe subjaz. Assim, uma tendência inclusiva, por exemplo, defenderá que as dificuldades sentidas pelas mulheres no interior da Igreja se devem à deturpação da mensagem inicial, ou da Tradição cristã, pelo que é em nome da fidelidade ao conteúdo essencial

${ }^{43}$ Russell,L. (1974), Human Liberation in a Feminist Perspective-a Theology, Philadelphia Westminster John Knox Press, p. 109. 
da mensagem cristã - a libertação - que se deve proceder a uma libertação da Palavra e a uma crítica da tradição que "traiu" a própria Tradição ${ }^{44}$.

A tendência exclusiva, por seu turno, consiste, em si mesma, num abandono do cristianismo, já que este é tido como inimigo das mulheres, estando os seus acontecimentos fundadores ligados a um homem, o que legitimou e fomentou estruturas sociais patriarcais ${ }^{45}$.

A tendência reconstrutiva, por fim, debruça-se sobre a possibilidade de reler o cristianismo à luz da luta das mulheres contra as estruturas patriarcais, quer no interior da Igreja, quer na sociedade, $\mathrm{em}_{\text {geral }}{ }^{46}$. Além disso, a hermenêutica feminista de uma tradição religiosa acentua a dimensão comunitário-grupal da interpretação da identidade própria. O horizonte comunitário de leitura poderá inspirar modelos pedagógicos que questionam um status quo aparentemente neutro, mas, na realidade, profundamente situado e marcado pelos "estipuladores" do discurso. (A título de exemplo, poder-se-á mencionar aqui a prática existente no interior do feminismo liberal judaico, que reconstrói e recria os textos, dando largas à criatividade permitida pelo próprio método exegético rabínico, de acordo com o qual, interpretar o texto é reescrevê-lo, actualizá-lo, prossegui-lo. O próprio acto de reenunciar o texto ou de fazer uma reapropriação criativa do mesmo, faz o seu conteúdo agir hoje e transforma o presente. Judith Plaskow ${ }^{47}$, por exemplo, propõe um midrash - interpretação exegética de um texto bíblico - feminista, que consiste numa reformulação

${ }^{44}$ Cf. por exemplo, Carr, A. (1990), Frauen verändern die Kirche. Christliche Tradition und feministische Erfahrung, Gütersloh: Gütersloher Verlag e Russell, L. (1979), The Future of Partnership, Philadelphia: Westminster John Knox Press; (1981), Growth in Partnership, Philadelphia: Westminster John Knox Press; (1974), Human Liberation in a Feminist Perspective - A Theology, Philadelphia: Westminster John Knox Press.

${ }^{45}$ Cf., por exemplo, Daly, M. (1985), Beyond God the Father. Towards a Philosophy of Women's Liberation. Boston: Beacon Press; (1986), Reine Lust. Elemental-feministische Philosophie (trad. do original americano: Pure Lust. Elemental-feminist Philosophy), Munique: Frauenoffensive; (1981), Gyn/Ökologie. Eine Meta-Ethik des radikalen Feminismus (trad. original americano: Gyn/Ecology. The Metaethics of Radical Feminism). Munique: Frauenoffensive. E ainda: Hampson, D. (1990), Theology and Feminism, Oxford: Oxford University Press.

${ }^{46}$ Ler-se-á como uma das autoras de referência incontornável nesta tendência: Fiorenza, E. S. (1987), In Memory of Her. A feminist theological reconstruction of Christian origins, Nova Iorque: Crossroads; (1992), But She Said: Feminist Practices of Biblical Interpretation, Boston: Beacon Press; (1993), Discipleship of Equals. A Critical Feminist Ekklesia-logy of Liberation, Nova Iorque: Crossroads; (1995), Bread not Stone: The Challenge of Feminist Biblica I Interpretation, Boston: Beacon Press; (1998), Sharing Her Word. Feminist Biblical Interpretation in Context, Boston: Beacon Press.

${ }^{47}$ Ler-se-á com muito proveito a sua obra brilhante Standing Again at Sinai (1990), San Francisco: Harper \& Row. 
do sacrifício de Isaac, encarado agora do ponto de vista de Sara, a mãe de Isaac. Enquanto o texto bíblico diz que Abraão parte com o seu filho para o sacrificar, à ordem de Deus, o midrash feminista diz que Sara se levanta de noite, entra na tenda do filho e lhe diz para ele fugir. Ou então, num segundo midrash, Sara revolta-se contra Deus e declara-se a sua desobediência. Um outro exemplo é o texto de Lilith, a primeira mulher de Adão, expulsa do Paraíso por ser demasiado insubmissa...).

Por último, poderá ser também objecto de discussão o horizonte último desta hermenêutica, em termos de objectivos a longo prazo. A tendência de algumas correntes feministas cristãs para recentrarem a tradição nas mulheres, por contraponto a uma tradição centrada nos homens, assim como a subsequente projecção no discurso teológico (em estrito senso) das mesmas imagens femininas, numa versão agora "feminina" de um Deus excessivamente "masculino" até há pouco, apresenta vantagens e desvantagens, retomando, nomeadamente, ainda que em chave teológica, a polémica de um feminismo ginocêntrico ou igualitário e da construção de um modelo sociocultural novo.

A teologia feminista presta um contributo precioso à teologia fundamental através da sua crítica de um discurso teológico que identifica Deus e a sua transcendência com imagens masculinas e com representações que o colocam numa atitude de indiferença face ao mundo criado. A crítica deste tipo de teologia chama a atenção para o carácter exclusivo e literal das imagens "patriarcais" de Deus. Estas conduzem o discurso teológico a uma atitude idolátrica, isto é, à veneração de uma representação de Deus e não do próprio Deus. A esta redução de Deus ao masculino corresponde uma negação implícita de uma parte da humanidade, isto é, das mulheres, enquanto imagem de Deus, uma vez que se exclui a possibilidade de um discurso acerca de Deus que utilize imagens e representações femininas. Simplesmente, correntes há também da teologia feminista que tendem a substituir uma unilateralidade por outra, exaltando agora o feminino como forma de fazer frente à exaltação milenar do masculino. Perguntar-se-á, pois, se este modelo levará longe e se não será útil o apelo a um horizonte de reflexão hermenêutica baseado na categoria-chave da alteridade. 
